\title{
EL ESTADO DE LA ARQUEOLOGÍA CLÁSICA EN ESPAÑA: PROPUESTAS PARA UN DEBATE NECESARIO
}

\section{CLASSICAL ARCHAEOLOGY IN SPAIN: PROPOSAL FOR A NECESSARY DEBATE}

\author{
por \\ MERCEDES ORIA SEGURA ${ }^{1}$
}

RESUMEN El artículo refleja el estado actual de la Arqueología Clásica en España, comentando las tendencias vigentes: la pervivencia de la escuela tradicional, la escasa implantación de los enfoques más recientes, desde la New Archaeology al materialismo y el post-procesualismo, y la tendencia a renovar los estudios tradicionales con nuevos temas y enfoques. Se defiende la necesidad de aplicar al estudio del mundo clásico una metodología puramente arqueológica, entendiendo la Arqueología como forma específica de hacer Historia en su más amplio sentido.

\begin{abstract}
This paper deals with the current trends of Classical Archaeology in Spain: the surviving of the traditional scholarship, the weak acceptance of recent theoretical approaches, from New Archaeo$\log y$ to Materialism and Post-processualism, and the trend to renew traditional studies with new themes and perspectives. It emphasizes the need of adopting a purely archaeological methodology in the study of the Classical World, understanding Archaeology as a specific method of doing History in its broadest sense.
\end{abstract}

\section{I.- LA ATENCIÓN AL MUNDO CLÁSICO}

\section{I.1.- La "escuela tradicional"}

La Arqueología Clásica es una de las especialidades con mayor tradición dentro de la Arqueología Histórica $^{2}$ y la causa es evidente. La cultura clásica en su más amplio sentido (pensamiento, literatura, arte, etc.) y en particular la griega, se reconoce como base de la cultura europea occidental. Esa cultura

1. Dpto. de Prehistoria y Arqueología, Proyecto “La formación de la Bética romana"(Ministerio de Educación, DGES, PB97-0736; Junta de Andalucía, II PAI, HUM-152).

2. Utilizo aquí el término "histórica" en el sentido convencional que se refiere al estudio de las culturas con escritura, por oposición a la arqueología prehistórica, ampliando el significado de la expresión anglosajona Historical Archaeology. En cuanto al carácter histórico de la Arqueología como disciplina, será ampliamente desarrollado a lo largo de este trabajo. 
se exporta como paradigma al resto del mundo que la óptica eurocéntrica considera "civilizado", incluyendo países que no han vivido directamente ese pasado (Morris 1994: 11-12; Andrén 1998: 10-11). Los restos arqueológicos griegos y romanos se encuentran a la vista en todo el Mediterráneo y desde el Renacimiento constituyen un modelo asumido, "clásico", al que se dedica una atención preferente.

El mundo clásico es aparentemente una realidad histórica incontestable y bien definida, cuyos límites establece la tradición historiográfica (v. Plácido 1993: 128-135; Padilla 1993: 29). Sin embargo esos límites (geográficos, cronológicos) son lo bastante amplios e indefinidos, como para abarcar una realidad multicultural de enorme complejidad. Por otra parte, la imagen del mundo clásico y el contenido de los estudios dedicados a él se han visto con el tiempo profundamente afectados por diversas corrientes historiográficas, con su correspondiente trasfondo ideológico. Desde que, en la segunda mitad del s. XVIII, el alemán J. J. Winckelmann planteó la Historia del Arte Antiguo como una búsqueda de la esencia del arte, guiada por los conceptos absolutos de belleza y perfección (Trigger 1992: 46), la Arqueología Clásica se ha movido en un terreno básicamente histórico-artístico, ocupándose en problemas formales de evolución estilística al margen en gran medida de la Historia. El pensamiento idealista alemán marca profundamente el desarrollo de esta arqueología entendida como Historia del Arte Antiguo, que interesa como manifestación de lo espiritual, del Zeitgeist hegeliano (Withley 1987). Ello determina el principal campo de atención de los arqueólogos clásicos, prácticamente hasta la actualidad, siguiendo una orientación historicista en sus interpretaciones y con el método crítico positivista como herramienta básica de trabajo. La escuela alemana domina sin discusión esta tendencia, dentro de la sólida tradición académica de la Altertumswissenschaft. Su evolución, la llamada "Arqueología filológica", pretende restituir las obras originales del arte antiguo a partir de sus copias y derivaciones. Esto implica el estudio directo y detallado de las piezas y sus modelos. En la práctica, convierte la Arqueología en una disciplina que describe monumentos aislados, con preferencia pertenecientes a las artes mayores, descontextualizándolos y agrupándolos por "especies", en orden a clasificarlos tipológicamente y buscar sus modelos. Carandini (1997: 29) señala como rasgo característico de la Historia del Arte precisamente la drástica selección de objetos al margen de la Historia.

La Arqueología Clásica practicada en España (y también en Portugal: v. Fabião 1997) es consecuencia directa de la que se desarrolla en toda Europa bajo esta orientación, dedicada al estudio de la Antigüedad griega y romana. En España se centra lógicamente en su pasado romano, pero también las noticias sobre la etapa prerromana conservadas en los autores clásicos y algunos de sus vestigios materiales son objeto de atención. Los estudiosos se ajustan en mayor o menor medida a las tendencias generales, propiciando un desarrollo que se ve limitado, sin embargo, por el carácter "provincial" de la Península Ibérica respecto a los centros de la civilización clásica y por las miras excesivamente localistas de muchos de los trabajos.

Puede decirse que la historia de la Arqueología Clásica se está haciendo en los últimos años. Las obras más conocidas de teóricos e historiadores de la Arqueología (p.e. las de Daniel 1981 y Trigger 1992) se han desentendido en gran medida de unos estudios considerados regresivos. Desde fines de los 80 el panorama está cambiando, en el sentido de propiciar una reflexión crítica sobre la historia de la Arqueología Clásica, sobre las causas de su situación actual y sobre sus perspectivas de futuro. Es un fenómeno interesante que esa reflexión afecte de forma mucho más directa a la Arqueología Griega, con trabajos muy clarificadores dentro de sus diversos enfoques (p.e. Snodgrass 1990, esp. el capítulo 1; Morris 1994 y en general Morris, ed. 1994; Shanks 1997), que a la Arqueología Romana (como excepción con más propuestas novedosas que verdadera historiografía, Scott, ed. 1993).

En los últimos diez años asistimos también en España a un auténtico auge de la investigación historiográfica, desde dos perspectivas (v. Bravo 1991: 213-214) que coinciden a grandes rasgos con las escuelas "tradicional" e "innovadora" en la investigación. La primera se ocupa con insistencia del progreso en los conocimientos sobre la Hispania romana (ciertas intervenciones en Arce-Olmos, eds. 1991; Beltrán-Gascó, eds. 
1994; Gascó-Beltrán, eds. 1995; Gimeno 1998; etc.), describiendo las aportaciones de estudiosos de diferentes épocas. Esto permite conocer cómo se recogió y elaboró la documentación que hoy conocemos y "rescatar" figuras poco conocidas de la investigación hispana. La segunda insiste, con una fuerte carga ideológica que corre el riesgo de distorsionar a posteriori los temas analizados (v. la crítica en Ferrer 1996: 109-110), en la vinculación de la Arqueología practicada en cada época con los poderes establecidos o como reacción a los mismos (Vázquez-Risch 1991; Díaz-Andreu 1993, 1995, 1997; Díaz-Andreu-Mora 1995, expresamente en pp. 25-26; Ruiz-Zapatero 1996; Mora-Díaz-Andreu, eds. 1997, etc.). Esta corriente presta especial atención a las interpretaciones sobre los pueblos prerromanos, pero no se ocupa específicamente de la Arqueología Clásica como disciplina. Una de las pocas excepciones (Fernández- García 1993) adopta un agresivo tono negativo (v. esp. p. 64), que parece ignorar las aportaciones más recientes.

Lo que esta historiografía nos presenta es una Arqueología Hispanorromana anclada prácticamente hasta hoy en la tradición histórico-artística, entendida como complemento de los estudios anticuaristas basados en textos, inscripciones y monedas. Durante largo tiempo sigue prevaleciendo la orientación historicista en las investigaciones (Vázquez - Risch 1991: 27-31). El aislamiento de la España franquista se ha aducido como una causa fundamental de este conservadurismo (Díaz-Andreu - Mora 1995: 36; Díaz-Andreu 1997: 20 ss. para esta etapa). El prestigio de la escuela alemana, firmemente asentada en nuestro país con el Instituto Arqueológico Alemán, la ha convertido en el modelo consciente o inconsciente de las últimas generaciones de arqueólogos clásicos españoles (Chapa 1988: 136), formados en la órbita de grandes personalidades de prestigio incuestionable y trabajos decisivos en su momento, como los profesores García y Bellido, Blanco o Balil. No podemos olvidar en el plano técnico las fundamentales aportaciones de Lamboglia: excavación estratigráfica, interés por la cerámica (Cortadella 1997). Los métodos de esta Arqueología Clásica tradicional son positivistas, como reflejan las publicaciones españolas más frecuentes (con cifras referidas a la investigación andaluza, Fernández García 1993): estudios monográficos de piezas o edificios aislados y catálogos de materiales (capiteles, esculturas, bronces, cerámica "de lujo", mosaicos), extendidos al ámbito de un yacimiento, un museo, una provincia actual o antigua, etc. Los restos se presentan bajo un aspecto monumental, descontextualizados y con poca atención a su función, salvo excepciones. Sus modelos siguen siendo los de la Arqueología filológica alemana del siglo XIX, con su búsqueda de originales y paralelos y su afinado análisis estilístico. Los ejemplos son abundantes y bien conocidos, por lo que no creo necesario aislar casos concretos. El alto nivel alcanzado en este campo y la utilidad de poseer repertorios ordenados de materiales son innegables. Pero no podemos perder de vista que edificios, esculturas o mosaicos se justifican en determinadas situaciones históricas y que deben ser éstas el verdadero objeto de atención, las que dan sentido a las catalogaciones y a las piezas aisladas.

Los estudios sobre cerámicas romanas de la Península Ibérica quedan un tanto al margen de estas líneas. La consideración de la cerámica como "fósil-guía" en la metodología arqueológica tradicional (así continúa definiéndola un reciente manual introductorio: Beltrán 1990: Introducción), sumada al carácter industrial y funcional del material estudiado, la hace más susceptible de un análisis "arqueológico" que de comentarios artísticos. En la tradición positivista, los principales estudios se dedican en principio a identificar las producciones locales con sus talleres, especialmente de ánforas y de terra sigillata, y a elaborar tipologías con el fin de establecer una secuencia cronológica. Recientes "estados de la cuestión" (Roca 1995, para la cerámica común; Roca 1998 para la sigillata; García Vargas 1998: 17-29 para las ánforas) confirman la continuidad de esta tendencia. Paralelamente, se analiza la dispersión de las cerámicas importadas. La aplicación de técnicas informáticas al análisis estadístico y el avance en los estudios de pastas permite renovar los análisis, al menos desde el punto de vista metodológico. En este sentido, un investigador como M. Beltrán, pionero en su momento con su riguroso estudio de las ánforas hispanas (Beltrán 1970) sigue la línea de las investigaciones francesas contemporáneas (v. Beltrán 1977). 
El concepto de arqueología impuesto desde los años 60-70 impulsa un estudio con perspectivas amplias de la cultura material, que desplaza la atención hacia los centros productores de cerámica y su funcionamiento. En los últimos años, la vajilla y sobre todo los envases anfóricos se han convertido en una de las bases habituales para las investigaciones sobre la economía antigua, en particular los sistemas de producción y el comercio a escala local e imperial (Blázquez 1981; Miró 1988; Alarcão-Mayet 1990; García Vargas 1998, etc.). Su estudio queda en manos, por tanto, de "historiadores de la Antigüedad" tanto o más que de los propios "arqueólogos" (según las divisiones académicas al uso), con un abanico de posiciones teóricas que van del historicismo continuista a perspectivas diferentes, como el análisis socioeconómico marxista o los estudios de mercado con enfoques de Arqueología Espacial.

\section{I.2.- Conflicto y reacción}

Al aferrarse a los esquemas descritos la Arqueología Clásica ha visto frenado su desarrollo, sobre todo frente a las últimas tendencias de la Arqueología en general, planteando una situación conflictiva. Tiende a ser menospreciada por los partidarios más entusiastas de la innovación teórica y metodológica (generalmente prehistoriadores) y su continuidad académica puede verse incluso cuestionada. En realidad, esta última postura es tan errónea como la de aquellos que defienden a ultranza un modelo decimonónico muy alejado de las actuales tendencias de la Arqueología. La supervivencia de la Arqueología Clásica tiene que venir de una necesaria renovación de sus planteamientos, que confirme su interés como aportación de primer orden al conocimiento de la Antigüedad clásica y su utilidad en la formación de los futuros arqueólogos.

Es cierto que la Arqueología Clásica ha sido la última en unirse al activo debate teórico y metodológico desarrollado en España desde mediados de los 70 y sobre todo en los 80, con la progresiva entrada de las tendencias anglosajonas (v. con datos estadísticos García Santos 1997), difícilmente aceptadas por los arqueólogos clásicos de mentalidad más tradicional. A partir de los años 60 , el movimiento norteamericano y británico conocido como New Archaeology ofrece a la Arqueología tradicional una alternativa de base antropológica. Su concepción podría resumirse en unos cuantos principios fundamentales: acento en la explicación de procesos culturales frente a la descripción de culturas históricas (de ahí el nombre de Arqueología Procesual), preferencia por el razonamiento hipotético-deductivo y enfoque cuantitativo en el tratamiento de los datos (v. Renfrew-Bahn 1993: 37). De la observación de comportamientos y fenómenos en diversas situaciones históricas se obtendrían unas constantes, unos modelos que permitirían predecir determinadas reacciones en situaciones similares y establecer las normas del comportamiento humano. Esta "revolución" tenía que entrar en colisión con la "Gran Tradición" filológica e históricocultural, dedicada de manera preferente al mundo oriental y clásico (v. Renfrew 1980 y Snodgrass 1985). Los teóricos de la New Archaeology se han desentendido en gran medida de las épocas históricas. De hecho, la mayoría de sus experiencias fructíferas se ha llevado a cabo en el ámbito de la Prehistoria, lo que ha llevado a cuestionar la validez real de sus métodos y propuestas fuera del mismo (Gutiérrez 1997: 99-100). Esta preferencia por las etapas prehistóricas, donde la metodología arqueológica es la única posible, explica la llamativa ausencia de la Arqueología Clásica en las obras historiográficas y teóricas más recientes. Sin embargo, en los últimos diez años los arqueólogos clásicos españoles han comenzado en la práctica a plantear nuevas líneas de investigación, en consonancia con diversas corrientes. El repaso que ofrezco a continuación no pretende ser de ningún modo exhaustivo (para ello remito a Fernández Ochoa-Roldán 1991), sino un simple muestrario de las tendencias existentes, a las que pueden añadirse otros muchos títulos y autores. 
Un grupo de investigadores propone temas y enfoques más o menos influidos por las propuestas de la New Archaeology. El ejemplo más claro está en los estudios sobre el poblamiento y el territorio en la Hispania romana desde el punto de vista de la Arqueología Espacial, con resultados desiguales (v. la serie Arqueología Espacial, trabajos como el de Fernández Corrales 1988 y, últimamente, las contribuciones españolas en Barker - Lloyd, eds. 1991, con la recensión de Mattingly 1993). En la actualidad esta línea ha evolucionado hacia la llamada "Arqueología del paisaje" (v. la puesta al día de Orejas 1991). Los actuales sistemas informáticos de análisis territorial se han convertido en la base indispensable de los estudios sobre poblamiento, acentuando más la innovación tecnológica que la propiamente teórica. Otras líneas de trabajo bien conocidas y de resultados contrastados, como la "Arqueología de la Muerte", apenas se han aplicado a la sociedad hispano-romana.

Los enfoques más recientes han encontrado una aceptación desigual (v. Keay - Díaz-Andreu 1997: 2-3). Se ha señalado el progresivo arraigo de las tendencias materialistas y funcionalistas, en sentido amplio, dentro de la investigación arqueológica española, aunque no expresamente en el terreno clásico. Por el contrario, la corriente post-procesual tiene por ahora pocos seguidores en España. Hodder (ed., 1987; 1988, 1991, 1994, etc.) se presenta como la cabeza de este movimiento teórico de fuerte impronta estructuralista, que él prefiere denominar Arqueología Contextual y que plantea el significado simbólico de los datos materiales, inteligibles dentro de su propio contexto global. El contexto se define (Hodder 1988: 167) como la "totalidad del medio relevante" a la hora de establecer el significado. Los arqueólogos postprocesuales o contextuales se interesan de nuevo por problemas históricos, por la sucesión de causas que conducen al hecho a explicar, dentro de la escala temporal de la longue durée definida por el historiador francés Braudel (Hodder, ed. 1987). Se ocupan de las expresiones de poder y conflicto social, del significado simbólico de la cultura material dentro de su contexto histórico, etc. Es decir, que se mueven en terrenos mucho más familiares a los arqueólogos de corte tradicional dedicados al mundo clásico (Dyson 1993), terrenos donde las fuentes textuales desempeñan un papel de enorme importancia a la hora de aclarar las interpretaciones. En el caso español, los procesos de cambio son los que reciben mayor atención en los últimos años (podemos arrancar con VV.AA. 1987), con intervención muy directa de investigadores británicos de tendencia post-procesual en los estudios sobre la P. Ibérica (Cunliffe - Keay, eds. 1995; DíazAndreu-Keay, eds. 1997; Keay, ed. 1998). En el fondo sus interpretaciones no son muy diferentes de las que propone la corriente "tradicional renovada" que enseguida mencionaré, insistiendo en la importancia de la ideología en relación con el cambio cultural (p.e. Keay 1997).

\section{II.- LA ARQUEOLOGÍA CLÁSICA COMO ARQUEOLOGÍA}

\section{II.1.- Un amplio marco común: la Arqueología dentro de la Historia}

La imagen de la Arqueología Clásica que hemos presentado es la de una disciplina que, después de siglos de inercia, comienza a moverse y titubea aún sobre la dirección a seguir. Para tomar una decisión es imprescindible definir con claridad qué entendemos por Arqueología Clásica y a dónde queremos llegar con ella. También es necesario descartar viejas actitudes y prejuicios, muy bien encarnados en su conflictiva relación con las disciplinas "afines" que también se ocupan del mundo clásico desde otras perspectivas: la Historia Antigua y la Historia del Arte Antiguo (sobre las diferencias metodológicas, Bravo 1991: 214-215, como "historiador de la Antigüedad").

En realidad el conflicto y las dificultades de adaptación proceden de un concepto de la Arqueología derivado, como tantos otros rasgos de nuestra disciplina, de la tradición decimonónica alemana. Ésta dota a los términos Vorgeschichte y Archäologie de un contenido cronológico y cultural (v. Snodgrass 1985: 31) 
y limita las actividades de la Arqueología a las épocas y culturas que cuentan con escritura, de manera muy especial a la clásica greco-romana, separándola radicalmente de la Prehistoria. El desarrollo académico de la Arqueología, bajo la fortísima influencia de la citada tradición, mantiene aún hoy en forma de dos áreas de conocimiento independientes esta división artificial (v. las observaciones de Querol 1997: 643), que equipara dos términos referidos a categorías diferentes. "Prehistoria" corresponde a una parcelación cronológica y cultural de la Historia, como una etapa de la vida de la Humanidad que de manera tradicional se identifica con el desconocimiento de la escritura. "Arqueología" hace referencia a una disciplina histórica que reconstruye e interpreta la actividad humana a partir de sus huellas materiales. Con sus métodos y técnicas puede afrontarse el estudio de la Prehistoria, de la época clásica y de cualquier otra etapa de la Historia. Trasladar esta aclaración al ámbito universitario supondría refundir a todos los arqueólogos, sea cual sea su especialidad cronológica y cultural, en un área única (v. la aportación de Lull en Junyent $e t$ alii 1993: 339-344, esp. 343), pero esta solución no parece viable por el momento, ya que tanto prehistoriadores como arqueólogos clásicos e históricos en general temen ver diluida su respectiva identidad. Matizando el nombre del área actual de Arqueología, que por su dedicación es de hecho un área de Arqueología Histórica, y coordinando los ámbitos de actuación sobre todo en el terreno académico, podría evitarse esta dificultad, salvando la unidad metodológica de la Arqueología.

Podemos entender la Arqueología como una disciplina autónoma dentro de un marco científico general, el conocimiento histórico. Si el objetivo general del historiador es hacer inteligible el pasado (Febvre 1953/1992: 69-70, 116, 133, en tono contundente), el arqueólogo afronta esa tarea, que podemos desarrollar como reconstruir y explicar los hechos y el comportamiento del hombre en el tiempo y en el espacio, a través fundamentalmente de los restos materiales. Así el arqueólogo se caracteriza como un tipo particular de historiador, que aplica los métodos científicos más acordes con su posición teórica a resolver los problemas planteados por los datos materiales, y desde luego, nunca como un técnico limitado a extraer información al servicio del historiador de base textual (v. la crítica al respecto de Coarelli 1994: 296, y su defensa del arqueólogo como historiador, 298 ss.). El enfoque arqueológico aporta a la Historia planteamientos distintos, consecuencia del tipo de documentación utilizada (sobre la compleja relación entre textos y cultura material, Andrén 1998: Cap. 6), y con frecuencia temas de investigación ajenos a la información escrita. La linealidad del texto escrito, reflejo de la estructura del lenguaje oral y de significado directamente accesible (Andrén 1998: 148), conlleva una construcción histórica igualmente lineal, expresada en forma narrativa, donde los hechos y las circunstancias que los rodean se presentan en sucesión cronológica. Por el contrario, los objetos y las huellas de la actividad humana se presentan de manera simultánea y su sentido no es siempre explícito ni se ordena en un discurso sucesivo. La información proporcionada se refiere más bien al contexto general de los "hechos históricos": el medio natural, las condiciones de vida, los condicionantes ideológicos, las formas de actuación a que dan lugar, etc. Ni textos ni objetos por sí solos consiguen dar una visión completa de la realidad a la que responden, ni constituyen dentro de ella categorías independientes y aisladas. En cuanto a la diferencia entre Arqueología Clásica e Historia del Arte Antiguo, reside en su objetivo más que en su objeto, ya que las obras de arte entran sin duda en la categoría de documentos arqueológicos, tanto como los fragmentos cerámicos o la distribución espacial de las necrópolis. Llevando esta idea al extremo, podría considerarse la Historia del Arte una parte de la Arqueología, idea que Carandini (1997: 221) atribuye a Bianchi Bandinelli en sus últimos tiempos. Por otra parte la Iconología, entendida como interpretación de la iconografía (Panofsky 1994), tiende a situar y explicar las imágenes en y por su contexto histórico, algo muy próximo a lo que hace el arqueólogo cuando se enfrenta a la Historia mediante sus huellas materiales. La revalorización de los significados contenidos en los objetos, en las imágenes, en los estilos y en sus códigos de utilización, inteligibles en contextos concretos, se cuenta entre los méritos de las corrientes estructuralistas y sus derivados más recientes en Arqueología, que 
pueden aportar perspectivas de gran interés a la Arqueología Clásica. En definitiva, los objetos de estudio de la Arqueología son mucho más amplios, como también lo son sus objetivos: la Arqueología aspira a la reconstrucción y explicación de la Historia: la lejana y la cercana, la que hace uso de textos y la que no, en sus más diversas facetas, a partir de todos los resultados materiales de la actividad humana y no sólo de los que conllevan implicaciones estéticas.

Todo ello supone partir de un concepto lo más amplio posible de la Historia, como proceso único que engloba todo lo que le ha sucedido a la Humanidad desde sus orígenes hasta la actualidad; y como ciencia que lo estudia con todos los instrumentos a su alcance. Se trata de una concepción muy próxima a la original de la llamada Escuela de los Annales (v. por ejemplo Febvre 1953/1992: 30), en realidad una tendencia amplia enfocada hacia la historia social, interesada por la totalidad de la actividad humana de cada sociedad y partidaria de presentar la Historia como problema (Bulliet 1992: 133), más que una verdadera escuela unificada. La cercanía de sus planteamientos con los de una Arqueología entendida como Historia ha sido ya señalada por diversos investigadores (Leone 1978: 30, citado en Knapp 1992: 10; v. también Bintliff, ed. 1991). El objetivo final de la Arqueología no es otro que el de hacer Historia, mientras la atención a los aspectos no narrativos de la misma y a los procesos de larga duración, consecuencia del tipo de documentación utilizada, conforma su carácter específico. No es por tanto una ciencia independiente, puesto que sus diversos encuadres teóricos y metodológicos y sus objetivos son los de la Historia, y a ésta conducen sus diferentes estrategias de investigación. El término "Ciencias de la Antigüedad", con el que se denominan a veces las disciplinas afines que se ocupan del mundo antiguo (Gómez - Caerols, eds. 1992), e incluso algunos Departamentos universitarios con una visión abierta de la Historia, es en ese sentido inexacto aunque operativo a niveles prácticos.

\section{II.2.- Presente y futuro de la Arqueología Clásica en España}

En definitiva, la Arqueología Clásica es ante todo Arqueología, ni identificada con la Historia del Arte, ni subordinada a la Historia Antigua de base textual. La relación no siempre ha sido fluida ni la delimitación de "competencias" fácil, pero desde un concepto global de la Historia, carece de sentido enfrentar a unas y otras. Así parece entenderlo en la actualidad la mayoría de los arqueólogos clásicos españoles. El grupo más numeroso de investigadores se propone renovar los estudios tradicionales sin renunciar a sus aportaciones, aproximándose a las posturas teóricas más favorables a una Arqueología entendida como Historia. Incluso en el campo aparentemente más inmovilista, el del arte hispano-romano, se transforma el contenido alejándose de las puras descripciones estilísticas. De nuevo son investigadores alemanes quienes marcan las pautas a seguir, proponiendo una renovación de temas tradicionales como la iconografía o la arquitectura pública. De este modo, en la tendencia a situar las imágenes en su contex to y comprobar su función, podemos citar exposiciones de escultura (p.e. VV.AA. 1990) y muchas de las aportaciones a las tres Reuniones sobre Escultura Romana en Hispania celebradas hasta ahora (Mérida, 1992, publicada en 1993; Tarragona, 1995, publicada en 1996; Córdoba, 1997, e.p.). Se empieza a hablar de programas decorativos en el ámbito doméstico (Koppel 1993; Puerta et al. 1994; Vaquerizo - Noguera 1997) y se presta especial atención a la imagen pública. En este terreno, interesa sobre todo cuál es el mensaje ideológico (político, religioso, social) que las imágenes transmiten a través de su contenido, su aspecto material, su distribución espacial, etc., en la línea de autores como Hölscher o Zanker. La monumentalidad creciente de las ciudades se presenta como resultado de una ideología deliberadamente transmitida por la administración imperial, que se refleja en el uso de determinados modelos decorativos en los espacios públicos (p.e. Trillmich 1995). Este enfoque se ha aplicado con entusiasmo a las ciudades hispanas (Trillmich-Zanker, eds. 1990 y trabajos posteriores en la misma línea, de alcance local o general). Se constata el interés por las pautas de implantación territorial 
(p.e. VV.AA. 1990b; Gorges - Salinas, eds. 1994) y el proceso de urbanización (Bendala 1989 en adelante). Los casos hispanos están habitualmente presentes en los congresos internacionales dedicados al urbanismo romano como fenómeno histórico, más allá del aspecto puramente arquitectónico. El mejor reflejo de ese interés es la celebración en una ciudad hispana, Tarragona, del Congreso Internacional de Arqueología Clásica de 1993 (VV.AA. 1994), dedicado monográficamente al tema y acompañado por una ilustrativa exposición (VV.AA. 1993).

Las líneas de investigación aquí presentadas son sólo unos ejemplos que no agotan ni los trabajos hoy en curso ni otras posibilidades de desarrollo. De ellos podemos concluir que, una vez liberada de esquemas desfasados, la Arqueología Clásica se abre a amplias perspectivas de desarrollo, como aportación esencial y plenamente arqueológica al conocimiento histórico del mundo antiguo griego y romano y sus ámbitos respectivos de expansión, el hispano-romano en nuestro caso. La Arqueología Clásica en la actualidad no se limita a confirmar o desmentir textos, ni a trabajar únicamente en los aspectos y etapas ignorados por las fuentes escritas, aunque así siguen presentando algunos autores (caso de Andrén 1998: 126) la Arqueología con perspectiva histórica. Tal como las de otros períodos y culturas, la Arqueología Clásica debe presentarse como una manera específica de conocer y explicar la historia del mundo clásico greco-romano, que toma como base restos materiales e integra su sentido con el de los demás datos en una construcción histórica global. La perspectiva histórica, tal como la plantea Morris (1994: 45-46), propone tener en cuenta tanto la evidencia conservada como la perdida (pero con frecuencia transmitida, entre otras por las fuentes escritas) y convertir en objeto de estudio no tanto los restos, como quienes los utilizaron para sus propios fines.

La renovación viene por tanto de la adecuada formulación de nuevas cuestiones, de afrontar la historia del mundo clásico sin depender de las líneas marcadas por la documentación escrita, aunque se pueda y se deba recurrir a ella siempre que aporte información útil. En ese sentido, es cierto que la Arqueología Clásica tendrá más en común con las de otras épocas históricas que con la Arqueología Prehistórica. Pero puede aproximarse tanto a ésta por planteamientos y metodología, como a la Historia Antigua tradicional por su objeto de estudio. El mundo clásico es un campo privilegiado donde desarrollar el concepto global de la Historia, utilizando todas las fuentes disponibles. Cuenta además con la ventaja de un material abundantísimo fruto de las investigaciones más antiguas, bien conocido y sistematizado en cuanto a catalogación, adscripción, cronología, etc., en un volumen mucho mayor que el de otras especialidades de creación más reciente. Ese material reinterpretado aún puede proporcionar respuestas. El resultado debe ser la vuelta de la Arqueología Clásica, en España y en el resto del mundo, a la posición de primera línea que le corresponde, tanto en el plano académico como en el ámbito general de la Arqueología. 


\section{BIBLIOGRAFÍA}

ALARCÃO, J.-MAYET, F., eds. (1990): As ânforas lusitanas. Tipologia. Produção. Comercio. Coimbra.

ANDRÉN, A. (1998): Between artifacts and texts. Historical archaeology in global perspective. Nueva York-Londres.

ARCE, J.-OLMOS, R., eds. (1991): Historiografía de la Arqueología y la Historia Antigua en España (siglos XVIII-XX). Madrid.

BARKER, G.-LLOYD, J., eds. (1991): Roman landscapes. Archaeological survey in the Mediterranean region (Roma, 1988). Londres.

BELTRÁN, M. (1970): Las ánforas romanas en España. Zaragoza.

BELTRÁN, M. (1977): "Problemas de la morfología y del concepto histórico-geográfico que recubre la noción tipo. Aportaciones a la tipología de las ánforas béticas”, en Méthodes classiques et méthodes formelles dans l'étude des amphores (Roma, 1974). Roma: 97-131.

BELTRÁN, M. (1990): Guía de la cerámica romana. Zaragoza.

BELTRÁN, J.-GASCÓ, F., eds. (1994): La Antigüedad como argumento. Historiografía de Arqueología e Historia Antigua en Andalucía. Sevilla.

BENDALA, M. (1989): "La génesis de la estructura urbana en la España antigua", CuPAUAM 16: 127-147.

BINTLIFF, J., ed. (1991): The Annales School and Archaeology. Leicester.

BLÁZQUEZ, J. Ma , ed. (1981): Producción y comercio del aceite en la Antigüedad (Madrid, 1980). Madrid.

BRAVO, G. (1991): "Elementos para un estudio de las tendencias en la historiografía española del último cuarto de siglo", en ARCE, J.-OLMOS, R., eds. (1991): 213-217.

BULLIET, R. W. (1992): “Annales and Archaeology”, en KNAPP, A. B., ed.: Archaeology, Annales and Ethnohistory. Cambridge: 131-134.

CARANDINI, A. (1997): Historias en la tierra. Manual de excavación arqueológica. Barcelona.

CHAPA, T. (1988): "Perspectivas actuales de la Arqueología española", Revista de Occidente 81: 135-142.

CHIC, G. (1997): Historia económica de la Bética en época de Augusto. Sevilla.

COARELLI, F. (1994): “L'archéologie classique dans le culture européenne d'aujourd'hui”, RA 1994-2: 294-302.

CORTADELLA, J. (1997): “El Profesor Nino Lamboglia (1912-1977) y la Arqueología Clásica española”, en MORA, G.-DÍAZ-ANDREU, M., eds. (1997): 553-563.

CUNLIFFE, B.-KEAY, S., eds. (1995): Social complexity and the development of towns in Iberia. Oxford.

DANIEL, G. (1981): Historia de la Arqueología. De los anticuarios a Gordon Childe. Madrid (2a ed.).

DÍAZ-ANDREU, M. (1993): "Theory and ideology in Archaeology: Spanish Archaeology under the Franco regime", Antiquity 67: 74-82.

DÍAZ-ANDREU, M. (1995): "Archaeology and nationalism in Spain”, en KOHL, P. L.-FAWCETT, C., eds.: Nationalism, politics and the practice of Archaeology. Cambridge: 39-56.

DÍAZ-ANDREU, M. (1997): "Conflict and innovation. The development of archaeological traditions in Iberia”, en DÍAZ-ANDREU, M.-KEAY, S., eds. (1997): 6-33.

DÍAZ-ANDREU, M.-KEAY, S., eds. (1997): The Archaeology of Iberia. The dynamics of change. LondresNueva York.

DÍAZ-ANDREU, M. - MORA, G. (1995): “Arqueología y política: el desarrollo de la Arqueología española en su contexto histórico", TP 52-1: 25-38.

DYSON, S. L. (1993): "From New to New Age Archaeology: archaeological theory and Classical Archaeology - a 1990s perspective", AJA 97: 195-206. 
FABIÃO, C. (1997): "Percursos da Arqueologia Clássica em Portugal: da Sociedade Archeologica Lusitana (1849-1857) ao moderno Projecto de Conimbriga (1962-1979)", en MORA, G.-DÍAZ-ANDREU, M., eds. (1997): 105-123.

FEBVRE, L. (1953/1992): Combats pour l'histoire. París / Combates por la historia. Barcelona.

FERNÁNDEZ, S.-GARCÍA, L. (1993): "Clásica Arqueología, Antigua Historia. Ensayo en torno a un desencuentro en la tradición historiográfica de Andalucía Occidental”, Spal 2: 57-79.

FERNÁNDEZ CORRALES, J. Ma (1988): El asentamiento romano en Extremadura y su análisis espacial. Cáceres.

FERNÁNDEZOCHOA,C.-ROLDÁN, L. (1991): “Arqueología hispano-romana: República y Alto Imperio”, Veinte años de Arqueología en España. Homenaje a Don Emeterio Cuadrado Díaz. BAEAA 30-31: 209-226.

FERRER, E. (1996): La España cartaginesa. Claves historiográficas para la historia de España. Sevilla.

GARCÍA SANTOS, J. C. (1997): "La Arqueología española de los 80. Una visión de las raíces teóricas", en MORA, G.-DÍAZ-ANDREU, M., eds. (1997): 685-694.

GARCÍA VARGAS, E. (1998): La producción de ánforas en la Bahía de Cádiz en época romana (siglos II a.C.-IV d.C.). Écija.

GASCÓ, F.-BELTRÁN, J., eds. (1995): La Antigüedad como argumento II. Historiografía de Arqueología e Historia Antigua en Andalucía. Sevilla.

GIMENO, H. (1998): "El descubrimiento de Hispania", en Hispania, el legado de Roma. En el año de Trajano. Zaragoza: 25-35.

GÓMEZ, J.-CAEROLS, J. J., eds. (1995): Antiqua Tempora. Reflexiones sobre las Ciencias de la Antigüedad en España. Madrid ( $2^{\mathrm{a}}$ ed.).

GORGES, J. G.-SALINAS, M., eds. (1994): Les campagnes de Lusitanie romaine. Occupation du sol et habitats (Salamanca, 1993). Madrid-Salamanca.

GUTIÉRREZ, S. (1997): Arqueología: introducción a la historia material de las sociedades del pasado. Alicante.

HODDER, I., ed. (1987): Archaeology as long-term history. Cambridge

HODDER, I. (1988): Interpretación en Arqueología. Corrientes actuales. Barcelona.

HODDER, I., ed. (1991): The meaning of things. Material culture and symbolic expression. Cambridge.

HODDER, I. (1994): Interpretación en Arqueología. Corrientes actuales. Barcelona ( $\left.2^{\mathrm{a}} \mathrm{ed}.\right)$.

JUNYENT, E. ET ALII (1993): "L'Arqueologia com a àrea de coneixement universitària", Revista d'Arqueologia de Ponent 3: 335-349.

KEAY, S. (1997): "Urban transformation and cultural change", en DÍAZ-ANDREU, M. - KEAY, S., eds. (1997): 192-210.

KEAY, S., ed. (1998): The romanisation of early Roman Baetica. JRA Supl. Portsmouth (R.I.).

KEAY, S.-DÍAZ-ANDREU, M. (1997): “Introduction”, en DÍAZ-ANDREU, M. - KEAY, S., eds. (1997): 1-5.

KNAPP, A. B. (1992): “Archaeology and Annales: time, space, and change”, en KNAPP, A. B., ed.: Archaeology, Annales and Ethnohistory. Cambridge: 1-21.

KOPPEL, E. Mª (1993): “Die Skulpturenausstattung römischer Villen auf der Iberischen Halbinsel”, Hispania Antiqua. Denkmäler der Romerzeit, Mainz: 193-203.

LEONE, M. (1978): 'Time in American Archaeology", en REDMAN, C. ET ALII, eds.: Social Archaeology. Nueva York: 25-36.

MATTINGLY, D. J. (1993): "Understanding Roman landscapes”, JRA 6: 359-366.

MIRÓ, J. (1988): La producción de ánforas en Catalunya. Un estudio sobre el comercio del vino en la Tarraconense (siglos I a.C.-I d.C.). B.A.R. International Series $n^{\circ} 473$. Oxford. 
MORA, G.-DÍAZ-ANDREU, M., eds. (1997): La cristalización del pasado: Génesis y desarrollo del marco institucional de la Arqueología en España. Málaga.

MORRIS, I. (1994): “Archaeologies of Greece”, en MORRIS, I. ed.: Classical Greece. Ancient histories and modern archaeologies. Cambridge: 8-47.

OREJAS, A. (1991): "Arqueología del paisaje: historia, problemas y perspectivas", AEspA 64: 191-230.

PADILLA, A. (1993): Introducción a la Historia Antigua. Sevilla.

PANOFSKY, E. (1994): Estudios sobre Iconología. Madrid, $9^{a}$ reimp.

PLÁCIDO, D. (1993): Introducción al Mundo Antiguo: problemas teóricos y metodológicos. Madrid.

PUERTA, C. ET ALII (1994): "La colección de esculturas halladas en Valdetorres del Jarama (Madrid)", AEspA 67: 179-200.

QUEROL, M ${ }^{a}$ A. (1997): "El concepto de Arqueología para la sociedad española del siglo XX/XXI", en MORA, G.-DÍAZ-ANDREU, M., eds. (1997): 635-645.

RENFREW, C. (1980): "The Great Tradition versus the Great Divide", AJA 84-3: 287-298.

RENFREW, C.-BAHN, P. (1993): Arqueología. Teoría, métodos y práctica. Madrid.

ROCA, M. (1995): "Estado actual de la investigación de las cerámicas comunes de época romana en la Península Ibérica", en AQUILUÉ, X.-ROCA, M., coords.: Ceràmica comuna romana d'època AltoImperial a la Península Ibèrica. Estat de la qüestió (Ampurias, 1994). Ampurias: 9-12.

ROCA, M. (1998): "Historia de la investigación de la terra sigillata hispanica", en FERNÁNDEZ, Mª I., ed.: Terra sigillata hispánica. Estado actual de la investigación. Jaén: 13-30.

RUIZ-ZAPATERO, G. (1996): "Celts and Iberians. Ideological manipulations in Spanish Archaeology", en GRAVES-BROWN, P. ETALII, eds.: Cultural identity and Archaeology. The construction of European Communities. Londres-Nueva York: 179-195.

SCOTT, E., ed. (1993): Theoretical Roman Archaeology. First Conference Proceedings. Aldershot-Brookfield. SHANKS, M. (1997): Classical Archaeology of Greece. Experiences of the discipline. Londres-Nueva York. SNODGRASS, A. M. (1985): "The New Archaeology and the classical archaeologist", AJA 89: 31-37. SNODGRASS, A. M. (1990): Arqueología de Grecia. Barcelona.

TRIGGER, B. (1992): Historia del pensamiento arqueológico. Barcelona.

TRILLMICH, W. (1995): “Gestalt und Ausstattung des «Marmorforums» Mérida: Kenntnisstand und Perspektiven”, MM 36: 269-291.

TRILLMICH, W. - ZANKER, P., eds. (1990): Stadtbild und Ideologie. Die Monumentalisierung hispanischer Städte zwischen Republik und Kaiserzeit (Madrid, 1987). Munich.

VAQUERIZO, D.-NOGUERA, J. M. (1997): La villa romana de El Ruedo (Almedinilla, Córdoba). Decoración escultórica e interpretación. Córdoba.

VÁZQUEZ, J. M.-RISCH, R. (1991): “Theory in Spanish Archaeology since 1960”, en HODDER, I., ed.: Archaeological theory in Europe. The last three decades. Londres: 25-51.

VV.AA. (1987): Los asentamientos ibéricos ante la romanización (Madrid, 1986). Madrid.

VV.AA. (1990): Espai públic i espai privat. Les escultures romanes del Museu de Sagunt, Sagunto.

VV.AA. (1990b): Les villes de Lusitanie romaine. Hierarchies et térritoires (Talence, 1988). Burdeos.

VV.AA. (1993): La ciudad hispanorromana. Catálogo de la Exposición. Barcelona.

VV.AA. (1994): XIV Congreso Internacional de Arqueología Clásica. La ciudad en el mundo romano (Tarragona, 1993). Tarragona.

WITHLEY, J. (1987): "Art history, archaeology and idealism: the German tradition", en HODDER, I., ed.: Archaeology as long-term History. Cambridge: 9-15. 